\title{
Usia Berpengaruh Dominan terhadap Perilaku Perawatan Luka Perineum pada Ibu Nifas di RSUD Sleman
}

\author{
Prasetya Lestari ${ }^{1}$ \\ 1 Universitas Alma Ata Yogyakarta \\ Jalan Ringroad Barat Daya No 1 Tamantirto, Kasihan, Bantul, Yogyakarta \\ Email: prasettya.lestari@gmail.com
}

\begin{abstract}
Abstrak
Perilaku perawatan luka perineum pada ibu nifas sangat penting. Hal ini berkaitan dengan rentan terhadap kejadian infeksi post partum. Ibu nifas perlu selalu menjaga kebersihan seluruh tubuhnya, pakaian yang dikenakannya serta kebersihan lingkungannya. Tujuan penelitian ini untuk menganalisis hubungan antara usia dan paritas dengan perilaku perawatan luka perineum pada responden. Penelitian ini dilaksanakan pada bulan Januari 2016 di RSUD Sleman Yogyakarta. Jenis penelitian ini korelasional dengan rancangan cross sectional. Populasi dalam penelitian ini seluruh ibu nifas di RSUD Sleman Yogyakarta dengan jumlah sampel 67 responden. Teknik sampling yang digunakan yakni accidental sampling. Instrument penelitian ini berbentuk kuesioner. Analisa data multivariat dengan uji regresi linear ganda. Hasil penelitian menunjukkan bahwa mayoritas responden berperilaku cukup dalam hal perawatan luka perineum pada ibu nifas (mean 18,37). Sebagain responden berusia 20-23 tahun (73,14\%). Mayoritas responden dengan paritas 1-2. Hasil analisis bivariat menunjukkan bahwa ada hubungan antara usia dengan perilaku perawatan luka perineum $(p=0,000, r=0,549)$, ada hubungan antara paritas dengan perawatan luka perineum $(p=0,000, r=0,535)$. Hasil analisis multivariat dengan regresi linier ganda menunjukkan bahwa antara usia dan paritas berhubungan signifikan dengan perawatan luka perineum pada ibu nifas, akan tetapi pada hasil uji t menunjukkan hasil bahwa usia lebih dominan berhubungan dengan perilaku perawatan luka perineum. Simpulan ada hubungan antara usia dan paritas dengan perilaku perawatan luka perineum pada ibu nifas di RSUD Sleman Yogyakarta. Usia lebih dominan berhubungan dengan perilaku perawatan luka perineum pada ibu nifas.
\end{abstract}

Kata Kunci: usia, paritas, perilaku perawatan luka perineum, ibu nifas

\section{Age Dominant Influence of Behavior Perineum Wound Care in The Postpartum Women Hospital Sleman}

\begin{abstract}
Behavior perineal wound care in postpartum mothers is very important. This is related to prone to the incidence of infection, mothers need to always maintain the cleanliness of the whole body, clothes and cleanliness of their environment. The purpose of this study to determine correlations between age and parity with perineal wound care behaviors among respondents. This study was conducted in January 2016 in Sleman Hospital District of Yogyakarta. This type of research is correlational with cross sectional design. The population in this study postpartum mothers in Sleman hospitals Yogyakarta with a sample of 67 respondents. The sampling technique that is accidental sampling. This research instrument in the form of questionnaires. Multivariate data analysis with multiple linear regression analysis. The results showed that the majority of respondents to behave fairly in terms of perineal wound care in the postpartum mother (mean 18.37). Sebagain respondents aged 20-23 years (73.14\%). The majority of respondents with parity 1-2. The results of the bivariate analysis showed that there is a relationship between age and behavior of perineal wound care $(p=0.000, r=0.549)$, there is a relationship between parity with perineal wound care $(p=0.000, r=0.535)$. Multivariate analysis with multiple linear regression showed that between age and parity significantly associated with perineal wound care in the postpartum mother, but the t test results showed that the dominant age relates to the behavior of
\end{abstract}


perineal wound care. Conclusion, there is relationship between age and parity with the behavior of perineal wound care postpartum mother at Sleman hospitals Yogyakarta. The age more dominant associated with behavior perineal wound care in postpartum mothers.

Keywords: age, parity, behavior perineal wound care, postpartum mother

Info Artikel:

Artikel dikirim pada 23 Mei 2016

Artikel diterima pada 29 Juni 2016

DOI : http://dx.doi.org/10.21927/jnki.2016.4(2).95-101

\section{PENDAHULUAN}

AKI menurut Survei Demografi Kesehatan Indonesia (SDKI) tahun 2012 sebanyak 359/100 ribu kelahiran hidup dan AKB 32/1000 kelahiran hidup (Depkes RI, 2013). Sedangkan target MDG's AKI 2015 102/100 ribu kelahiran hidup dan AKB 23/1000 kelahiran hidup. Penyebab kematian ibu di Indonesia meliputi perdarahan $(30,5 \%)$, infeksi $(22,5 \%)$ dan gestosis $(17,5 \%)(1)$.

Angka kematian ibu di Daerah Istimewa Yogyakarta (DIY) menurut Dinkes DIY (2013) angka kematian ibu dilaporkan sebesar 87,3 per 100.000 kelahiran hidup dan angka kematian bayi (AKB) 25 per 1.000 kelahiran hidup. Berdasarkan data tersebut, maka masalah kematian ibu dan kematian bayi merupakan hal yang serius yang harus diupayakan penurunannya agar target MDG's dapat dicapai (1).

Salah satu penyebab infeksi postpartum, karena adanya luka pada bekas perlukaan plasenta, laserasi pada saluran genital termasuk episiotomi pada perineum, dinding vagina dan serviks (1). Luka pada perineum akibat episiotomi ruptura uteri atau laserasi merupakan daerah yang tidak mudah kering (2). Angka kejadian infeksi karena episiotomi masih tinggi, diperkirakan insiden trauma perineum atau episiotomi dialami $70 \%$ wanita yang melahirkan pervaginam sedikit banyak mengalami trauma perineal.

Robekan jalan lahir merupakan penyebab kedua perdarahan setelah atonia uteri yang terjadi pada hampir persalinan pertama dan tidak jarang juga pada persalinan berikutnya. Luka biasanya ringan tetapi kadang-kadang terjadi juga luka yang luas dan berbahaya. Sebagai akibat persalinan terutama pada seorang primipara, biasa timbul luka pada vulva di sekitar introitus vagina yang biasanya tidak dalam, akan tetapi kadang-kadang bisa timbul perdarahan banyak (3).
Menjaga kebersihan bagi ibu nifas sangatlah penting karena ibu nifas sangat rentan terhadap kejadian infeksi,ibu perlu selalu menjaga kebersihan seluruh tubuhnya, pakaian yang di kenakannya serta kebersihan lingkungannya. Anjuran pada ibu nifas salah satunya untuk membersihkan daerah kelamin dengan sabun dan air setiap kali selesai BAK/BAB. Membersihkan di mulai dari daerah sekitar vulva dari depan ke belakang, baru kemudian membersihkan daerah sekitar anus (4).

Berdasarkan hasil studi pendahuluan yang telah dilakukan di RSUD Sleman Yogyakarta didapatkan data persalinan spontan pada bulan Oktober-Desember 2014 sebanyak 201 persalinan spontan, dari jumlah yang mengalami infeksi tersebut di lakukan episiotomi dan mengalami laserasi jalan lahir tanpa episiotomy sebanyak 150 dari bulan Oktober-Desembar 2014. Upaya yang dilakukan untuk menurunkan AKI adalah upaya Safe Motherhood.Safe Motherhood dirintis untuk mengatasi perbedaan yang sangat besar antara AKI di negara maju dengan negara berkembang. Upaya Safe Motherhood merupakan upaya untuk menyelamatkan perempuan agar kehamilan dan persalinannya dapat dilalui dengan sehat dan aman, serta menghasilkan bayi yang sehat.Tujuan upaya Safe Motherhood adalah untuk menurunkan angka kesakitan ibu hamil, bersalin, nifas, disamping menurunkan angka kesakitan dan kematian bayi baru lahir.

Tujuan penelitian ini untuk mengetahui distribusi frekuensi usia responden, jumlah paritas pada responden dan mengetahui hubungan antara paritas dengan perilaku perawatan luka perineum pada responden. Untuk mengetahui hubungan antara paritas dengan perilaku perawatan luka perineum pada respondn serta mengetahui korelasi antara usia dan paritas dengan perilaku perawatan luka perineum pada responden 


\section{BAHAN DAN METODE}

Penelitian ini dilaksanakan pada bulan Januari 2016 di RSUD Sleman Yogyakarta. Jenis penelitian ini korelasional dengan rancangan cross sectional. Populasi dalam penelitian yakni seluruh ibu nifas di RSUD Sleman Yogyakarta dengan jumlah sampel 67 responden ibu nifas. Teknik sampling yang digunakan yakni accidental sampling. Instrument penelitian ini berbentuk kuesioner. Instrumen peneilitian dibuat sendiri oleh peneliti dengan terlebih dahulu dilakukan uji validitas indtrumen di RSUD Panembahan Senopati Bantul pada bulan September 2015 terhadap 20 responden ibu nifas dengan pernyataan 30 item dan setelah dilakukan uji validitas yang valid ada 27 item dan yang tidak valid ada 3 item. Reliabilitas instrumen nilai alpha 0,688 . Analisis data yang digunakan yakni analisis multivariat dengan uji regresi linear ganda.

\section{HASIL DAN BAHASAN}

\section{Analisis Univariat Karakteristik Responden}

Distribusi frekuensi karakteristik ibu nifas berdasarkan usia, pendidikan, pekerjaan, dan paritas disajikan dalam Tabel 1.

Tabel 1. Distribusi Frekuensi Karakteristik Ibu Nifas di RSUD Sleman

\begin{tabular}{lcc}
\hline Karakteristik & $\mathbf{n}$ & $\mathbf{\%}$ \\
\hline Umur & & \\
$<20$ tahun & 9 & 13,43 \\
$20-35$ tahun & 49 & 73,14 \\
$>35$ tahun & 9 & 13,43 \\
Pendidikan & & \\
SD & 21 & 31,30 \\
SMP & 27 & 40,30 \\
SMA & 19 & 28,40 \\
Pekerjaan & & \\
IRT & 54 & 80,60 \\
Swasta & 4 & 6,00 \\
PNS & 9 & 13,40 \\
Paritas & & \\
1 & 27 & 40,30 \\
2 & 27 & 40,30 \\
3 & 9 & 13,40 \\
4 & 2 & 3,00 \\
5 & 2 & 3,00 \\
Jumlah & 67 & 100 \\
\hline
\end{tabular}

Sumber: Data Primer Tahun 2016

Berdasarkan Tabel 1 karakteristik reponden menunjukkan bahwa sebagian besar responden di
RSUD Sleman Yogyakarta berada pada usia 20-35 tahun yaitu sebanyak 49 orang $(73,14 \%)$. Mayoritas responden berpendidikan SMP yaitu sebanyak 27 orang $(40,30 \%)$. Mayoritas responden memiliki pekerjaan sebagai IRT sebanyak 54 orang $(80,60 \%)$. Mayoritas responden di RSUD Sleman Yogyakarta memiliki jumlah anak 1 dan 2 masing-masing sebanyak 27 orang $(40,30 \%)$.

Tabel 2. Distribusi Skor Perilaku Ibu Nifas Berdasarkan Perilaku Perawatan LukaPerineum

\begin{tabular}{lc}
\hline Indikator & Perilaku \\
\hline Mean & 18,37 \\
Median & 20,00 \\
Mode & 15 \\
Std. Deviation & 4,093 \\
Minimum & 11 \\
Maximum & 26 \\
\hline
\end{tabular}

Sumber: Data Primer Tahun 2016

Berdasarkan Tabel 2 menunjukkan bahwa sebagian besar responden di RSUD Sleman Yogyakarta memiliki nilai 15 dalam hal perilaku perawatan luka perineum dikategorikan cukup. Nilai rata-rata perilaku respon yakni 18,37 dengan kategori cukup. Dapat disimpulkan bahwa perilaku perawatan luka perineum pada responden dikategorikan cukup.

\section{Analisis Bivariat}

Hasil analisis menggunakan pearson product moment untuk variabel paritas dan usia disajikan dalam Tabel 3.

Tabel 3. Hasil Analisis Pearson Product Moment

\begin{tabular}{lcc}
\hline Variabel & Pearson Correlation & Sig. (2-tailed) \\
\hline Paritas & 0,535 & 0,000 \\
Usia & 0,549 & 0,000 \\
\hline
\end{tabular}

Sumber: Data Primer Tahun 2016

Berdasarkan Tabel 3 menunjukkan bahwa ada hubungan positif antara paritas dengan perilaku perawatan luka perineum dengan kekuatan hubungan sedang $r=0,535$. Arah korelasinya searah, berarti semakin besar nilai paritas semakin besar pula nilai perilaku perawatan luka perineum pada ibu nifas. Ada hubungan positif antara usia dengan perilaku perawatan luka perineum denagn kekuatan hubungan tingakt sedang $(r=0,549)$. Arah korelasi searah, berarti dapat diinterpretasikan semakin besar nilai usia semakin besar pula nilai perilaku perawatan luka perineum pada ibu nifas. 


\section{Analisis Mulivariat}

Hasil uji regresi linier ganda untuk mengetahui pengaruh variabel paritas dan usia disajikan dalam Tabel 4.

Tabel 4. Hasil Uji Regresi Linier Ganda

\begin{tabular}{lll}
\hline Parameter & Nilai & Sig. \\
\hline Uji F & 16,114 & 0,000 \\
$\mathrm{R}$ & 0,579 & \\
$\mathrm{R}^{2}$ & 0,335 & \\
Adjusted $\mathrm{R}^{2}$ & 0,315 & \\
\hline
\end{tabular}

Berdasarkan Tabel 4 di atas nilai sig. pada uji F sebesar 0,000 sehingga dapat disimpulkan bahwa dengan tingkat kepercayaan 95\% secara bersamasama variabel paritas dan usia berpengaruh signifikan terhadap perilaku perawatan luka perineum pada ibu nifas. Nilai Sumbangan efektif variabel bebas terhadap variabel terikat dapat dilihat dari adjusted $R$ square yakni sebesar 0,335 . Dapat diinterpretasikan bahwa sumbangan efektifitas paritas dan usia terhadap perilaku perawatan luka perineum sebesar $33,5 \%$ sehingga $66,5 \%$ diberikan oleh variabel lain.

Tabel 5. Hasil Analisis Uji t

\begin{tabular}{lccc}
\hline & $\begin{array}{c}\text { Unstandardized } \\
\text { Coefficients } \\
\text { Beta }\end{array}$ & t & Sig. \\
\hline (Constant) & 7,531 & 2.542 & 0,013 \\
Paritas & 1,376 & 1.804 & 0,076 \\
Usia & 0,277 & 2.173 & 0,034 \\
\hline
\end{tabular}

Berdasarkan Tabel 5 di atas dapat diperoleh hasil persamaan regresi linier ganda dengan rumus $Y$ $=7,531+1,376 \mathrm{X}_{1}+0,277 \mathrm{X}_{2}$, konstanta (a) sebesar 58,867 , berarti jika tidak ada variabel usia dan paritas nilai perilaku perawatan luka perineum pada ibu nifas sebesar 7,531.

Nilai koefisien 1,376 menunjukkan bahwa peningkatan paritas sebesar 1, maka akan memberikan kenaikan perilaku perawatan perineum sebesar 1,376. Dapat diinterpretasikan bahwa paritas memberikan perubahan besar dan positif pada perilaku perawatan luka perineum pada ibu nifas. Nilai koefisien 0,277 menunjukkan bahwa setiap kenaikan 1 pada variabel usia akan memberikan kenaikan nilai perilaku perawatan luka perineum sebesar 0,277.

Nilai uji t menunjukkan tingkat signifikansi konstanta dan variabel independent. Signifikansi variabel konstanta sig. $=0,013<0,05$ ini menunjukkan bahwa konstanta mempengaruhi secara signifikan dalam regresi ganda. Signifikansi variabel paritas sig. $=0,076>0,05$ menunjukkan bahwa paritas tidak berpengaruh secara signifikan dalam regresi ganda. Signifikansi variabel usia sig. $=0,034<0,05$ menunjukkan bahwa usia berpengaruh secara signifikan dalam regresi ganda.

Pada umumnya, masa nifas cenderung berkaitan dengan proses pengembalian tubuh ibu ke kondisi sebelum hamil, dan banyak proses diantaranya yang berkenaan dengan proses involusi uterus, disertai dengan penyembuhan pada tempat plasenta dan luka pada perineum. Keberhasilan involusi tersebut sangat penting untuk kesehatan ibu, tetapi selain dari pedoman nutrisi dan saran yang mendasar tentang higiene dan gaya hidup (5).

Infeksi postpartum yang merupakan penyebab kematian maternal pada urutan kedua setelah perdarahan jika tidak segera ditangani (6). Infeksi postpartum terjadi di traktus genitalia setelah kelahiran yang diakibatkan oleh bakteri, hal ini akan meningkatkan resiko infeksi postpartum yang salah satunya disebabkan oleh luka episiotomi yang dapat menyebabkan syok septic (7).

Infeksi perineum dapat dihindari bahkan penyembuhan dapat dipercepat bila dilakukan perawatan secara cepat dan tepat, perawatan yang tidak tepat dapat merugikan pasien. Nyeri perineum merupakan sumber masalah yang signifikan bagi banyak perempuan setelah melahirkan, tidak hanya pada periode pascalahir langsung tetapi juga dalam jangka panjang.Luka pasca episiotomi harus dirawat dengan benar sehingga luka cepat sembuh dan tidak terjadi infeksi (5).

Hasil penelitian ini menunjukkan bahwa sebagian responden berperilaku cukup dalam hal perawatan luka perineum. Hal ini diinterpretasikan dari nilai mean perilaku perawatan luka perineum pada responden yakni 18,37 . Perilaku perawatan luka perineum pada responden dikategorikan cukup.

Keseberhasilan perilaku tentunya dipengaruhi oleh beberapa faktor baik secara internal maupun eksternal. Pada penelitian ini, berdasarkan hasil analisis bivariat bahwa antara paritas dan usia memiliki pengaruh terhadap perilaku perawatan perineum pada ibu nifas dengan keeratan hubngan tingkat sedang $(>0,5)$. Hasil penelitian ini sesuai dengan penelitian yang dilakukan oleh Darling $B$ 
pada penelitian perawatan diri ibu nifas di Madurai menunjukkan hasil bahwa ada korelasi positif antara paritas dengan perawatan diri ibu nifas (8).

Melalui pengalaman di masa lalu seseorang dapat belajar cara merawat diri. Apabila ibu sudah mengenal manfaat perawatan diri atau tehnik yang akan dilakukan, maka ibu akan lebih mudah dalam melakukan perawatan diri pascasalin. Dalam hal ini pengalaman memberikan pengaruh pada perilaku ibu untuk melakukan perawatan diri pascasalin. Pengalaman ibu dimana ibu yang multipara akan lebih realistis dalam mengantisipasi keterbatasan fisiknya dan dapat lebih mudah beradaptasi terhadap peran dan interaksi sosialnya, dukungan dimana ibu yang mendapat dukungan dapat memperkaya kemampuan menjadi orangtua dan mengasuh anak (9). Menurut Stright, ada faktor-faktor yang berpengaruh dalam perawatan diri Ibu pascasalin adalah faktor pengalaman pascasalin meliputi sifat persalinan, jumlah kelahiran, tujuan kelahiran, persiapan persalinan/kelahiran, peran menjadi orang tua sebelumnya (10).

Aktivitas merawat diri akan berbeda pada setiap individu. Hal ini juga dapat dipengaruhi oleh, usia, pendidikan, karakter, keadaan kesehatan, tempat lahir, budi pekerti,kebudayaan. Pada Ibu usia muda perawatan pascasalin yang dilakukanakan berbeda dengan lbu yang memiliki usia lebih dewasa. Demikian juga dengan pendidikan semakin tinggi pendidikan Ibu, maka kepeduliannya terhadap perawatan diri semakin baik.

Pada analisis multivariat dengan regresi linier ganda bahwa kedua variabel, baik variabel paritas maupun variabel usia memiliki pengaruh yang signifikan dalam regersi linier ganda. Namun pada korelasi dengan uji t variabel usia lebih dominan memberikan perngaruh pada regresi linier. Perilaku perawatan perawatan perineum di pengaruhi oleh faktor predisposisi. Adapun faktor predisposisi yang sangat berpengaruh dalam perilaku menurut Notoadmodjo yakni usia, paritas, pendidikan, sikap, pekerjaan, kebudayaan dan pengetahuan. Selain paritas, usia berpengaruh dalam perilaku perawatan luka perineum.hal ini sesuai dengan teori bahwa usia menunjukkan perkembangan kemampuan untuk belajar dan bentuk perilaku pengajaran yang dibutuhkan. Usia dapat mempengaruhi kematangan fisik, psikis dan kognitifseseorang. Kematangan seseorang dapat berkembang dengan belajar dari diri sendiri atau pengalaman orang lain (11).
Hal ini sesuai dengan Penelitian yang dilakukan oleh Harijati, didapatkan bahwa 26 responden $(86,67 \%)$ berperilaku positif tentang vulva hygiene dan 4 responden $(13,33 \%)$ berperilaku negative tentang vulva hygiene (12). Hal ini dipengaruhi oleh umur yang matang, tingkat pendidikan dan informasi yang didapat.

Penelitian Chasanah menyatakan perilaku perawatan luka perineum yang banyak dilakukan yaitu pada perilaku membersihkan daerah kelamin setiap kali selesai buang air besar sebanyak 40 responden (100\%) (13). Perilaku perawatan luka perineum yang paling jarang dilakukan yaitu pada perilaku mencuci tangan dengan air dan sabun sebelum membersihkan daerah kelaminnya sebanyak 35 responden $(87,5 \%)$. Hasil penelitian berdasarkan bahan dan alat menunjukkan bahwa sebagian besar responden di RSUD Sleman Yogyakarta menggunakan alat dan bahan yang benar yaitu 62 orang $(92,54 \%)$ dan besar responden yang menggunakan alat dan bahan dengan salah yaitu 5 orang $(7,46 \%)$ yang disebabkan oleh kebiasaan responden yang membersihkan luka perineum tidak menggunakan sabun dan betadin.

Menurut Andriani, faktor yang berhubungan dengan perawatan luka perineum antara lain yaitu kemampuan ibu dalam menyediakan sarana dan prasarana dalam perawatan luka perineum, misalnya kemampuan dalam menyediakan antiseptic (14). Agar luka jahitan perineum tidak terjadi infeksi maka menggunakan pembalut yang bersih setiap 4-6 jam sekali kemudian eratkan sehingga pembalut tidak bergerak maju mundur, setiap kali cebok menggunakan sabun dan luka bisa diberi betadin (15).

Menurut Harijati, perawatan vulva dilakukan setiap pagi dan sore sebelum mandi, sesudah buang air kecil atau buang air besar. Cara perawatan vulva dimulai dari cuci tangan sebelum dan sesudah melakukan perawatan luka, setelah BAK atau BAB cebok dari arah depan ke belakang, ganti pembalut setiap kali basah atau setelah BAK dan BAB (12).

Menurut Notoatmodjo, perilaku merupakan respon atau reaksi seseorang terhadap stimulus atau rangsangan dari luar organisme (orang) yang dipengaruhi oleh beberapa faktor diantaranya, faktor predisposisi antara lain adalah pengetahuan dan sikap seseorang terhadap kesehatan (16). Faktor yang mungkin antara lain adalah sarana prasarana atau fasilitas kesehatan. 
Berdasarkan hasil analisis sumbangan efektif usia dan paritas sebesar 33,55 sehingga dapat disimpulkan masih ada faktor lainyang berhubungan dengan perilaku perawatan luka perineum pada ibu nifas. Faktor-faktor yang mempengaruhi perilaku diantaranya adalah emosi, persepsi, motivasi, belajar, dan intelgensia. Suatu usaha untuk mengembangkan kepribadian dan kemampuan di dalam dan di luar sekolah dan berlangsung seumur hidup. Pendidikan mempengaruhi proses belajar seseorang, makin tinggi pendidikan seseorang makin mudah orang tersebut untuk menerima informasi (17). Menurut Tarwaoto dan Wartonah, personal hygiene diperngaruhi oleh faktor body image, status sosial, pengetahuan, budaya, kebiasaan dan kondisi fisik (18). Hasil ini sesuai dengan penelitiannya Dennis, pada fase early postpartum, ibu nifas memerlukan bantuan dan dukungan dari keluarga (19).

Menurut Harijati, akibat dari perawatan perineum yang tidak benar dapat mengakibatkan kondisi perineum yang terkena lokea dan lembab akan mengakibatkan perkembangan bakteri yang dapat menyebabkan timbulnya infeksi perineum (12). Munculnya infeksi pada perineum dapat merambat pada saluran kandung kencing ataupun pada jalan lahir yang dapat berakibat pada munculnya komplikasi infeksi pada kandung kencing maupun pada jalan lahir.

Infeksi tidak hanya menghambat proses penyembuhan luka tetapi dapat juga menyebabkan kerusakan pada jaringan sel penunjang, sehingga akan menambah ukuran dari luka itu sendiri, baik panjang maupun kedalaman dari luka itu sendiri.

\section{SIMPULAN DAN SARAN}

Berdasarkan hasil dan bahasan dapat disimpulkan bahwa mayoritas responden ibu dengan usia 20-35 tahun, mayoritas responden berpendidikan SMP, mayoritas responden sebagai IRT, dan mayoritas responden memiliki anak 1-2. Hasil analisis bivariat menunjukkan bahwa terdapat hubungan antara usia dengan perilaku perawatan luka perineum dan terdapat hubungan antara paritas dengan perilaku perawatan lukaperineum dengan tingkat korelasi antar variabel bebas yakni dalam tingkatan sedang. Berdasarkan analisis multivariat regresi linier ganda, hasil penelitian menunjukkan bahwa faktor usia memiliki pengaruh yang dominan terhadap perilaku perawatan luka perineum pada ibu nifas di RSUD Sleman.
Bagi tenaga medis hendaknya perlu memberikan pendidikan kesehatan yang lebih baik terhadap pasien terutama dalam hal perawatan luka perineum dengan harapan pasien mampu berperilaku yang lebih baik dalam perawatan luka perineum untuk mencegah terjadinya infeksi nifas. Bagi peneliti selanjutnya diharapkan untuk meneliti lebih lanjut terkait faktor lain yang berpengaruh terhadap perilaku perawatan luka perineum pada ibu nifas.

\section{RUJUKAN}

1. Depkes RI. Angka Kematian Ibu di Indonesia. Jakarta; 2012.

2. Manuaba. Ilmu Kebidanan Penyakit Kandungan Dan Keluarga berencana Untuk Pendidikan Bidan. Jakarta: EGC; 2010.

3. Rukiyah AY. Asuhan Kebidanan (Patologi Kebidanan). Jakarta: Trans Info Media; 2010.

4. Dewi VNL, Sunarsih T. Asuhan Kebidanan pada Ibu Nifas. Jakarta: Salemba Medika; 2011.

5. Boyle. Pemulihan Luka. Jakarta: EGC; 2008.

6. Hamilton. Dasar-Dasar Keperawatan Maternitas. Jakarta: EGC; 2006.

7. Cunningham FG. Obstetri Williams. Jakarta: EGC; 2005.

8. Darling BJ, Benjamin BA. Knowledge And Attitude Of Postnatal Mothers Regrarding Self Care Aftar Childbirth Selected Maternity Centres In Madurai. J Sci. 2014;4(1):40-4.

9. Bobak, Duncan M. Perawatan Maternitas dan Ginekologi Bandung. Yayasan Ikatan Alumni Pendidikan Keperawatan Pajajaran Bandung; 2008.

10. Stright. Panduan Belajar Perawatan Ibu dan Balita. Jakarta: EGC; 2005.

11. Potter PA, Perry AG. Fundamental Keperawatan Buku 1. 7th ed. Jakarta: Salemba Medika; 2009.

12. Harijati. Gambaran Perilaku Ibu nifas Tentang Vulva Hygiene Di RB/BKIA Ny. Harijati. Ponorogo; 2012.

13. Chasanah. Gambaran Perilaku Ibu Nifas Dalam Perawatan Luka Perineum Di Kelurahan Kabupaten Brebes. J Poltek Tegal. 2015;4(1):65-7.

14. Andriani Y. Perilaku Merawat Luka Perineum Ibu Nifas di Wilayah Kerja Puskesmas Darma Rini Kabupaten Temanggung. Semarang; 2015.

15. 15. Eisenberg. Handbook of Child Psychology Sixth Edition. New Jersey: John Willey \& Sons Inc; 2006. 
16. Notoatmodjo S. Promosi Kesehatan dan IImu Perilaku. Jakarta: Rineka Cipta; 2003.

17. Handayani R. Gambaran Tingkat Pengetahuan Ibu Nifas Tentang Perawatan Luka Perineum yang Benar di RSUD Surakarta Tahun 2012. 2012.

18. Tarwoto, Wartonah. Kebutuhan Dasar Manusia dan Proses Keperawatan. 4th ed. Jakarta: Salemba Medika; 2010.
19. Dennis C-L, Fung K, Grigoriadis S, Robinson GE, Romans S, Ross L. Traditional postpartum practices and rituals: a qualitative systematic review. Women's Heal [Internet]. 2007 Jul;3(4):487-502. Available from: http://www.futuremedicine.com/ doi/abs/10.2217/17455057.3.4.487 